\title{
Substrate Integrated Slot Array Antenna with Required Radiation Pattern Envelope
}

\author{
M. M. Zhou, Y. J. Cheng, and W. N. Huang \\ Fundamental Science on Extreme High Frequency Laboratory, School of Electronic Engineering, \\ University of Electronic Science and Technology of China, Chengdu 611731, China
}

Correspondence should be addressed to Y. J. Cheng; chengyujian@uestc.edu.cn

Received 3 January 2016; Accepted 15 February 2016

Academic Editor: Giuseppe Mazzarella

Copyright (C) 2016 M. M. Zhou et al. This is an open access article distributed under the Creative Commons Attribution License, which permits unrestricted use, distribution, and reproduction in any medium, provided the original work is properly cited.

A substrate integrated slot array antenna with a prescribed radiation pattern is investigated in this paper. To meet the requirement of a certain standard radiation pattern envelope, the array configuration and the element excitation coefficient should be considered together. An efficient and systematic method is proposed to determine the element number and element weights in a planar array. After that, the geometrical dimension of the substrate integrated slot array can be synthesized. As an example, a $K$-band $16 \times 22$ slot array antenna based on the substrate integrated waveguide (SIW) technology is designed, fabricated, and measured. Its radiation pattern can meet the class 3 antenna radiation pattern envelope of the European Telecommunications Standards Institute (ETSI) standard pattern. Experimental results are in good agreement with simulated ones.

\section{Introduction}

Substrate integrated waveguide (SIW) antennas have advantages of low loss, low profile, and ease of integration with other planar circuits [1-9]. In practice, it is often necessary to design an antenna array that will yield a desired pattern shape. A very common request is to design an SIW array antenna, whose far-field pattern exhibits low sidelobes [10-17]. These designs only consider how to lower the sidelobe level (SLL) but do not consider how to conform to a desired radiation pattern envelope. Shaped beam is important and essential for an antenna array. For example, an antenna array applied in the European microwave point-to-point communication system should meet the standardized radiation pattern envelope, which is defined by the European Telecommunications Standards Institute (ETSI) [18].

It could be difficult to achieve the ETSI standardized radiation pattern if a conventional low SLL synthesis method is used. To synthesize an SIW antenna array with the desired radiation pattern envelope and gain, the antenna array configuration and the element excitation coefficient should be considered together. On one hand, the array gain depends on the array configuration, the element weights, and the array efficiency. On the other hand, except the element weights, the realizable radiation pattern shape is also determined by the array configuration, that is, the element number and spacing. Thus, an efficient and systematic method is introduced in this paper to provide a fast and accurate solution for this problem.

To validate the correctness of the proposed method, a $K$-band SIW longitudinal slot array antenna with a proper feeding structure is synthesized to meet the class 3 antenna radiation pattern envelope $(20 \sim 24 \mathrm{GHz})$ of the ETSI standard document. It is fabricated and experimented.

\section{Design of an SIW Slot Array with Desired Radiation Pattern Envelope}

In this section, the design procedure for an SIW slot array antenna is introduced to achieve a desired radiation pattern envelope. A design flow diagram is presented in Figure 1.

Firstly, the SIW dimension is determined. a represents the SIW width, $s$ represents the spacing between adjacent metallic posts, and $d$ represents the metallic post diameter. Generally speaking, the element spacing is $a$ in $E$-plane. The SIW equivalent width, $w_{r w g}$, can be calculated by [19]

$$
w_{r w g}=a-s\left(0.766 e^{0.4482 d / s}-1.176 e^{-1.214 d / s}\right) .
$$




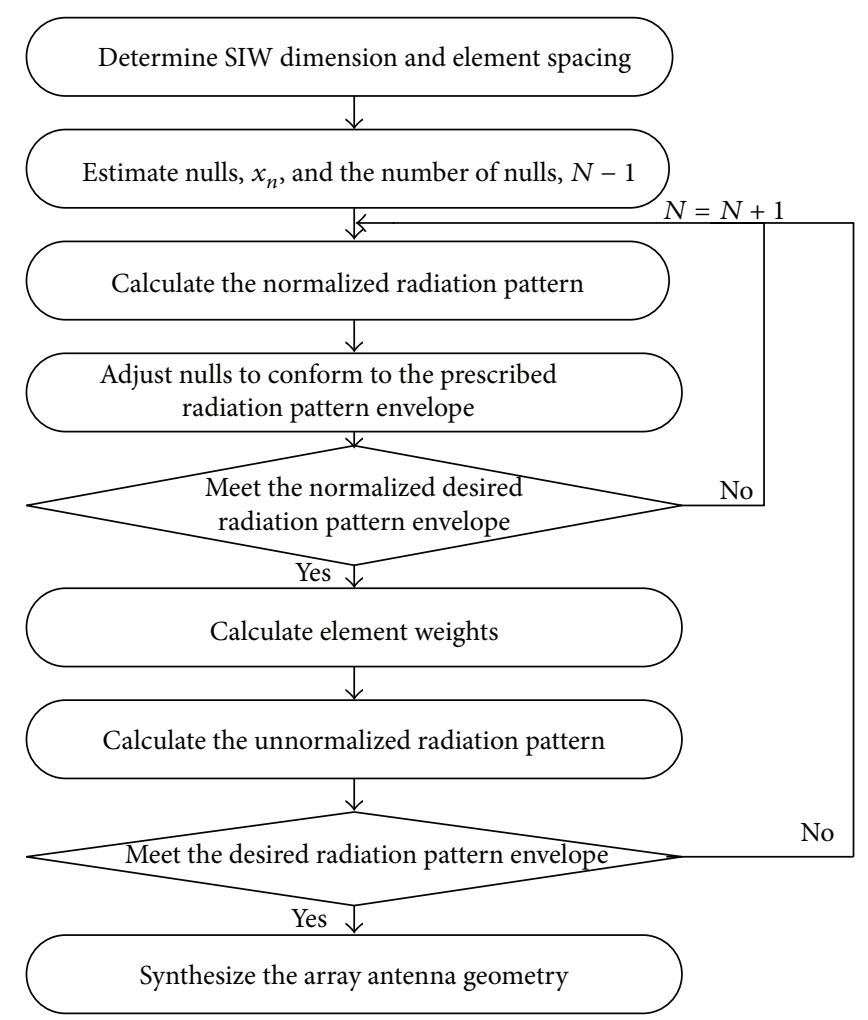

FIGURE 1: Design flow diagram for an SIW slot array antenna with a desired radiation pattern envelope.

Thus, the guide wavelength, $\lambda_{g}$, can be calculated by

$$
\lambda_{g}=\frac{2 w_{r w g}}{\sqrt{\left(2 w_{r w g} f_{0} \sqrt{\varepsilon_{r}} / c_{0}\right)^{2}-1}} .
$$

In (2), $f_{0}$ represents the center frequency, $\varepsilon_{r}$ is the dielectric permittivity, and $c_{0}$ is the light speed in vacuum. In order to locate slots at standing wave peaks, the slot spacing of such an array in $\mathrm{H}$-plane is often chosen as half of the guide wavelength at the center frequency.

When the radiation pattern is synthesized to be below a prescribed radiation pattern envelope, the array configuration and the element weights should be considered together. To simplify the synthesis, the isotropic element is used in this stage. The synthesis of a two-dimensional array antenna can be treated in two parts composed of equal-spacing linear synthesis problems for the principal planes, that is, $E$-plane and $H$-plane, respectively.

The array radiation pattern, with respect to the gain at the starting angle of azimuth relative to main beam axis, can be transformed to a polynomial function as follows. In the ETSI standard, the starting angle of azimuth is usually $5^{\circ}$ :

$$
f(x)= \begin{cases}\prod_{n=1}^{M}\left(\frac{x^{2}-x_{n}^{2}}{x_{g}^{2}-x_{n}^{2}}\right), & N=2 M+1 \\ \frac{x}{x_{g}} \prod_{n=1}^{M-1}\left(\frac{x^{2}-x_{n}^{2}}{x_{g}^{2}-x_{n}^{2}}\right), & N=2 M .\end{cases}
$$

In (3), $N$ represents the element number, $x_{n}$ represents the location of the nulls, and $x_{g}$ represents the location of the normalized point

$$
x=\cos \left(\frac{\beta e_{s}}{2} \cos (\theta)\right) .
$$

In (4), $e_{s}$ represents the element spacing. The initial location of the nulls can be estimated by

$$
x_{n}=\cos \left(\frac{n \pi}{N}\right), \quad 1 \leq n<\frac{N}{2} .
$$

In (5),

$$
N>\frac{\lambda_{0}}{e_{s}} \sqrt{\frac{G_{R}}{4 \pi}} .
$$

In (6), $G_{R}$ represents the array gain.

Then, the location of the nulls is adjusted to make (3) conform to the prescribed radiation pattern envelope, which is also normalized with respect to the gain at the starting angle of azimuth. The furthest sidelobe is controlled by the minimal $x_{n}$. When the furthest sidelobe decreases below the envelope, the next null $x_{n-1}$ is adjusted to control the next sidelobe. At last, the first sidelobe is made below the normalized ETSI radiation pattern envelope. Once the main beam cannot satisfy the required pattern at the current order, the number of nulls should be added for the polynomial function. If the shaped pattern is implemented, the element weights can be obtained by the coefficient of

$$
\begin{aligned}
& f(z) \\
& = \begin{cases}\prod_{n=1}^{M}\left(z^{2}+\left(2-4 x_{n}^{2}\right) z+1\right), & N=2 M+1 \\
(z+1) \prod_{n=1}^{M-1}\left(z^{2}+\left(2-4 x_{n}^{2}\right) z+1\right), & N=2 M .\end{cases}
\end{aligned}
$$

When the element weights in two linear arrays are obtained, the planar array element weights are equal to the product of two linear array weights. In this case, the array aperture efficiency can be estimated by [20]

$$
\eta_{a}=\frac{\left\|\sum_{m, n=1}^{E_{\mathrm{EN}}, H_{\mathrm{EN}}} I_{m n}\right\|^{2}}{E_{\mathrm{EN}} H_{\mathrm{EN}} \sum_{m, n=1}^{M, N}\left\|I_{m n}\right\|^{2}} .
$$

In (8), $E_{\mathrm{EN}}$ is the element number in $E$-plane, and $H_{\mathrm{EN}}$ is the element number in $H$-plane. $I_{m n}$ is the array element weight. Then, the array realized gain can be estimated by

$$
G=\eta_{f} \eta_{a} \frac{4 \pi E_{\mathrm{EN}} H_{\mathrm{EN}} a \lambda_{g}}{\lambda_{0}^{2}} .
$$

In (9), $\eta_{f}$ represents the feeding efficiency. Here, it is set as 1 to have sufficient design margin. By use of $G$, the calculated array radiation pattern based on (3) can be unnormalized and then compared with the desired radiation pattern envelope 


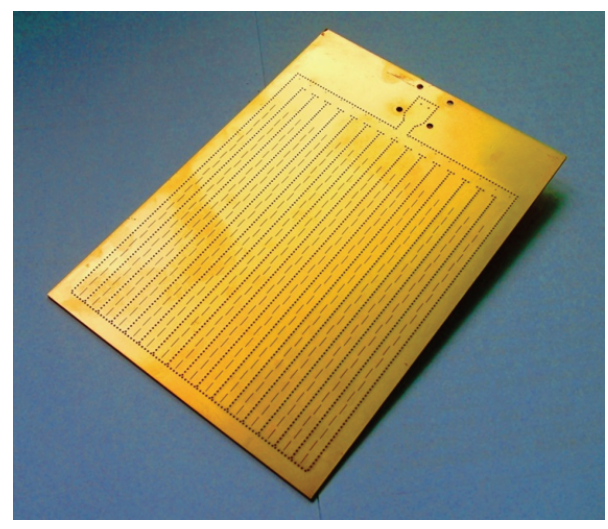

Figure 2: Photograph of the fabricated $16 \times 22$ SIW slot array antenna.

again. If it does not meet the ETSI standard pattern, the polynomial function will be adjusted and be synthesized again.

According to the above discussion, each slot weight has been known. Then, initial parameters of each slot can be synthesized through Elliott's iterative procedure [21] or the method of moment [22]. In this work, the slot length and the offset can be adjusted, and the slot width keeps unchanged. At last, the planar array antenna is modeled in HFSS and fullwave optimized.

\section{Design Results}

As an example, a $16 \times 22$ slot array antenna is designed to meet the class 3 antenna radiation pattern envelope (20 $24 \mathrm{GHz}$ ) of the ETSI standard pattern. It is designed based on the Taconic TLY-5 substrate with a thickness of $1.52 \mathrm{~mm}$. The permittivity and loss tangent of the substrate are 2.2 and 0.0009 , respectively. This design includes a 1-to-16 alternating phase power divider and a waveguide-to-SIW transition. The antenna works at the center frequency of $23 \mathrm{GHz}$. The SIW width is $7.2 \mathrm{~mm}$, the spacing between adjacent metallic posts is $1.5 \mathrm{~mm}$, and the metallic post diameter is $0.8 \mathrm{~mm}$.

The designed SIW slot array antenna is fabricated as shown in Figure 2. Its reflection coefficient is measured by a vector network analyser. The measured result compared with the simulated one is presented in Figure 3. The $-10 \mathrm{~dB}$ reflection coefficient bandwidth is more than $700 \mathrm{MHz}$.

The copolarized and cross-polarized radiation patterns in $E$-plane and $H$-plane of the array antenna are measured in a microwave anechoic chamber. As shown in Figures 4 and 5 , patterns within the desired frequency band are all below the ETSI pattern envelope. Besides, the tested antenna gain is $26.77 \mathrm{dBi}, 27.28 \mathrm{dBi}$, and $26.78 \mathrm{dBi}$ at $22.015 \mathrm{GHz}, 23 \mathrm{GHz}$ and $23.085 \mathrm{GHz}$, respectively. It can be seen that the measured antenna gain is more than $26.0 \mathrm{dBi}$ within the frequency range of $170 \mathrm{MHz}$. The radiation efficiency is $74.3 \%$ at the center frequency.

\section{Conclusion}

In this paper, a systemic method is proposed to design a substrate integrated slot array antenna with the required

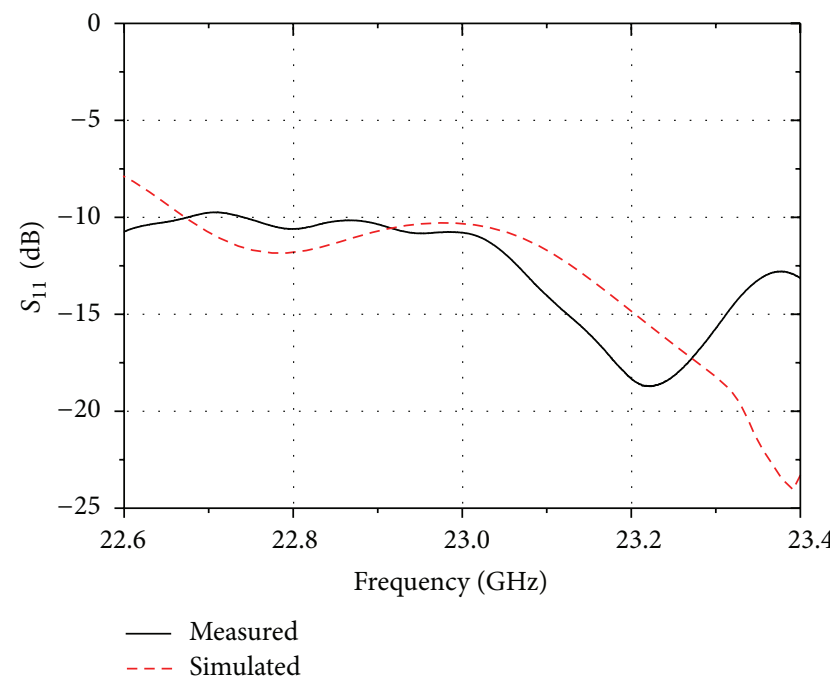

FIgURE 3: Reflection coefficients of the fabricated $16 \times 22$ SIW slot array antenna.

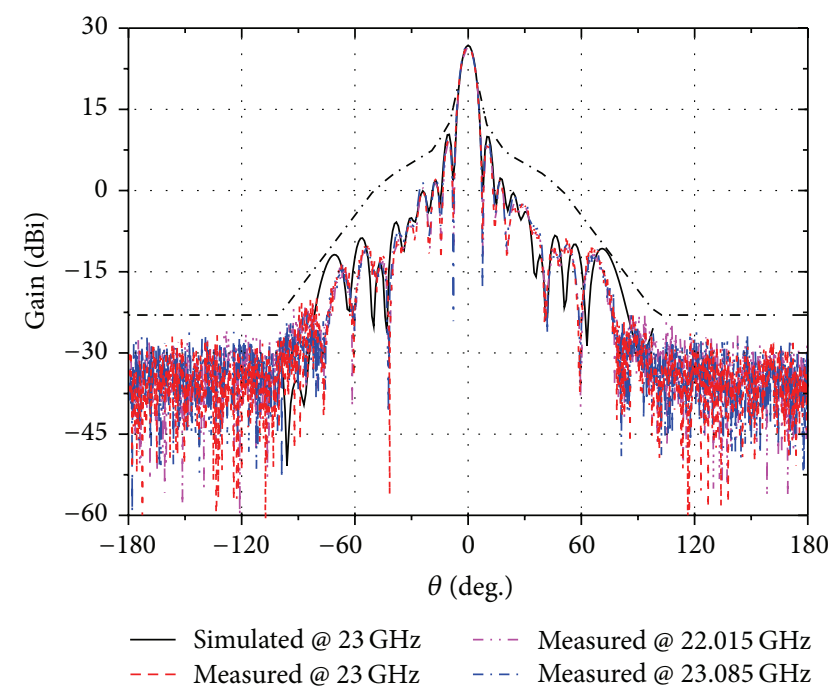

FIGURE 4: Simulated and measured patterns in E-plane of the fabricated $16 \times 22$ SIW slot array antenna.

antennas radiation pattern envelope. To validate the correctness of our design, an SIW slot array antenna with the class 3 radiation pattern envelope $(20 \sim 24 \mathrm{GHz})$ of the ETSI standard pattern is fabricated and measured. Measured results are in good agreement with simulated ones. It conforms to the ETSI standard document and the array antenna gain is more than $26 \mathrm{dBi}$ within the whole interested frequency range.

\section{Conflict of Interests}

The authors declare that there is no conflict of interests regarding the publication of this paper.

\section{Acknowledgments}

The authors would like to thank Taconic Corp. for providing sample substrates. This work is supported in part 


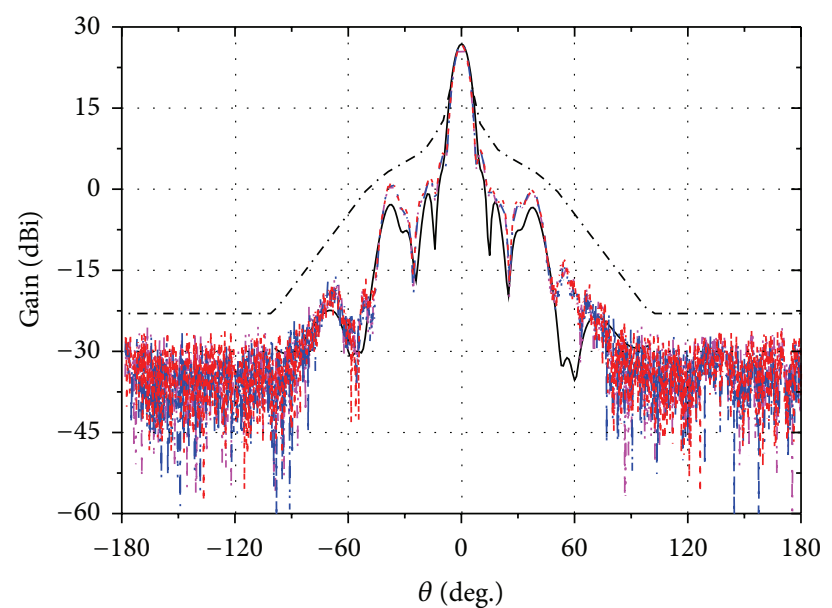

_ Simulated@ $23 \mathrm{GHz} \quad$-..- Measured @ $22.015 \mathrm{GHz}$ _._. Measured@ $23 \mathrm{GHz}$ _... Measured @ $23.085 \mathrm{GHz}$

Figure 5: Simulated and measured patterns in $H$-plane of the fabricated $16 \times 22$ SIW slot array antenna.

by Science Foundation for Distinguished Young Scholars of Sichuan Province under 2015JQO005, in part by Fundamental Research Funds for the Central Universities under grant ZYGX2014Z008, in part by Program for New Century Excellent Talents in University under grant NCET-13-0089, in part by the Foundation for the Author of National Excellent Doctoral Dissertation of China under grant no. 201338, and in part by the National Program for Support of Top-Notch Young Professionals.

\section{References}

[1] G. Q. Luo, Z. F. Hu, L. X. Dong, and L. L. Sun, "Planar slot antenna backed by substrate integrated waveguide cavity," IEEE Antennas and Wireless Propagation Letters, vol. 7, pp. 236-239, 2008.

[2] H. Vettikalladi, O. Lafond, and M. Himdi, "Membrane antenna arrays fed by substrate integrated waveguide for V-band communication," Microwave and Optical Technology Letters, vol. 55, no. 8, pp. 1746-1752, 2013.

[3] X. H. Zhang, G. Q. Luo, and L. X. Dong, "Substrate integrated waveguide fed cavity backed slot antenna for circularly polarized application," International Journal of Antennas and Propagation, vol. 2013, Article ID 316208, 6 pages, 2013.

[4] Q. D. Huang, Y. J. Cheng, and J. L. W. Li, "Surface-loaded ferrite substrate integrated waveguide switch," IEEE Microwave and Wireless Components Letters, vol. 25, no. 4, pp. 232-234, 2015.

[5] D. F. Guan, Y. S. Zhang, Z. Qian, and J. G. Zhang, "Compact circular polarised SIW array antenna with high gain and conical-beam," Electronics Letters, vol. 51, no. 24, pp. 1962-1964, 2015.

[6] W. N. Huang, Y. J. Cheng, and H. Deng, "Substrate integrated waveguide leaky-wave antenna conforming to conical shape surface," International Journal of Antennas and Propagation, vol. 2015, Article ID 359670, 7 pages, 2015.

[7] C. Zhang, J. Wang, M. Chen, Z. Zhang, and Z. Li, "A new kind of circular polarization leaky-wave antenna based on substrate integrated waveguide," International Journal of Antennas and Propagation, vol. 2015, Article ID 397960, 6 pages, 2015.

[8] J. Wu, Y. J. Cheng, and Y. Fan, "A wideband high-gain highefficiency hybrid integrated plate array antenna for V-band inter-satellite links," IEEE Transactions on Antennas and Propagation, vol. 63, no. 4, pp. 1225-1233, 2015.

[9] Y. J. Cheng and X. L. Liu, "W-band characterizations of printed circuit board based on substrate integrated waveguide multiresonator method," IEEE Transactions on Microwave Theory and Techniques, vol. 64, no. 2, pp. 599-606, 2016.

[10] J. F. Xu, W. Hong, P. Chen, and K. Wu, "Design and implementation of low sidelobe substrate integrated waveguide longitudinal slot array antennas," IET Microwaves, Antennas and Propagation, vol. 3, no. 5, pp. 790-797, 2009.

[11] X.-P. Chen, K. Wu, L. Han, and F. He, "Low-cost high gain planar antenna array for 60-ghz band applications," IEEE Transactions on Antennas and Propagation, vol. 58, no. 6, pp. 21262129, 2010.

[12] Z.-C. Hao, M. He, and X. Liu, "Planar high gain antenna for $42.0 \mathrm{GHz}$ Q-LINK PAN system," Microwave and Optical Technology Letters, vol. 56, no. 9, pp. 2098-2103, 2014.

[13] D.-Y. Kim and S. Nam, "Excitation control method for a low sidelobe SIW series slot array antenna with $45^{\circ}$ linear polarization," IEEE Transactions on Antennas and Propagation, vol. 61, no. 11, pp. 5807-5812, 2013.

[14] Y. J. Cheng, H. Xu, D. Ma, J. Wu, L. Wang, and Y. Fan, "Millimeter-wave shaped-beam substrate integrated conformal array antenna," IEEE Transactions on Antennas and Propagation, vol. 61, no. 9, pp. 4558-4566, 2013.

[15] S. E. Hosseininejad, N. Komjani, H. Oraizim, and M. T. Noghani, "Optimum design of SIW longitudinal slot array antennas with specified radiation patterns," Applied Computational Electromagnetics Society Journal, vol. 27, no. 4, pp. 320325, 2012.

[16] B. Y. El Khatib, T. Djerafi, and K. Wu, "Three-dimensional architecture of substrate integrated waveguide feeder for fermi tapered slot antenna array applications," IEEE Transactions on Antennas and Propagation, vol. 60, no. 10, pp. 4610-4618, 2012.

[17] H. Yang, G. Montisci, Z. Jin, Y. Liu, X. He, and G. Mazzarella, "Improved design of low sidelobe substrate integrated waveguide longitudinal slot array," IEEE Antennas and Wireless Propagation Letters, vol. 14, pp. 237-240, 2015.

[18] Harmonized European Standard (Telecommunications Series), Fixed Radio Systems, Characteristics and Requirements for Point-to-Point Equipment and Antennas, http://www.etsi.org/.

[19] K. Zamzam and J. Bornemann, "Designing the width of substrate integrated waveguide structures," IEEE Microwave and Wireless Components Letters, vol. 23, no. 10, pp. 518-520, 2013.

[20] R. J. Mailloux, Phased Array Antenna Handbook, Artech House, Boston, Mass, USA, 1994.

[21] R. S. Elliott, Antenna Theory and Design, IEEE Press, 2003.

[22] H. Y. Yee, "The design of large waveguide arrays of shunt slots," IEEE Transactions on Antennas and Propagation, vol. 40, no. 7, pp. 775-781, 1992. 


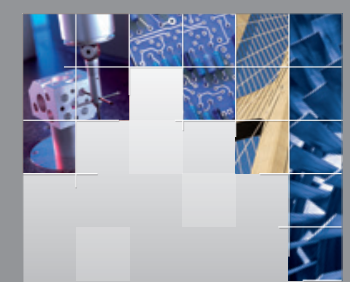

\section{Enfincering}
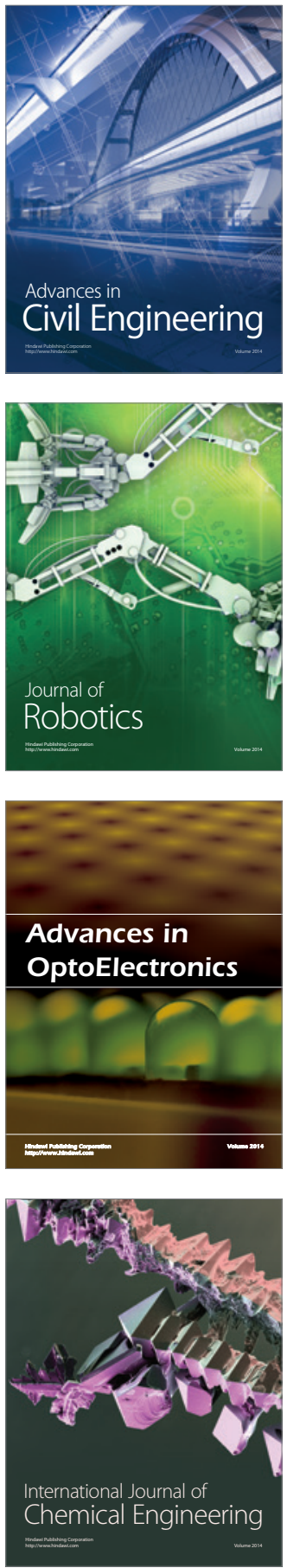

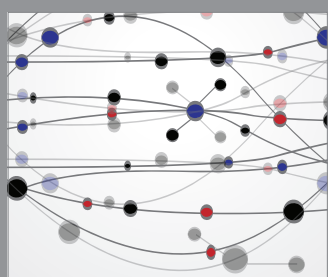

The Scientific World Journal

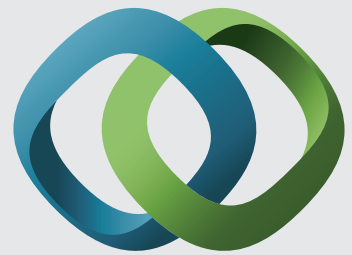

\section{Hindawi}

Submit your manuscripts at

http://www.hindawi.com
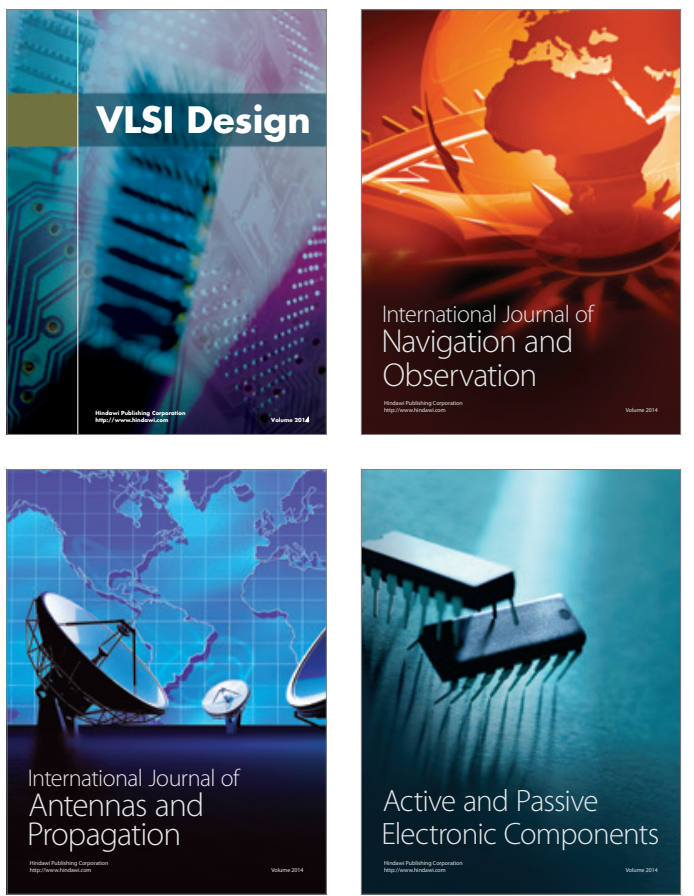
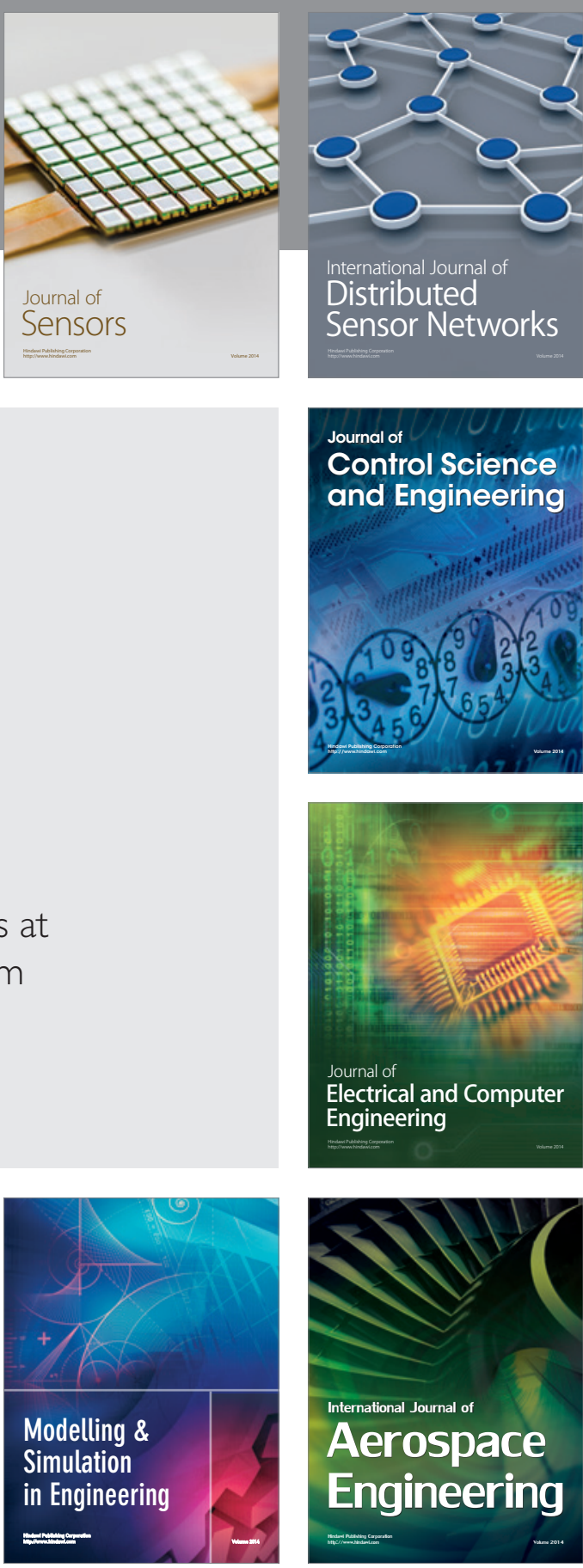

International Journal of

Distributed

Sensor Networks

Journal of

Control Science

and Engineering
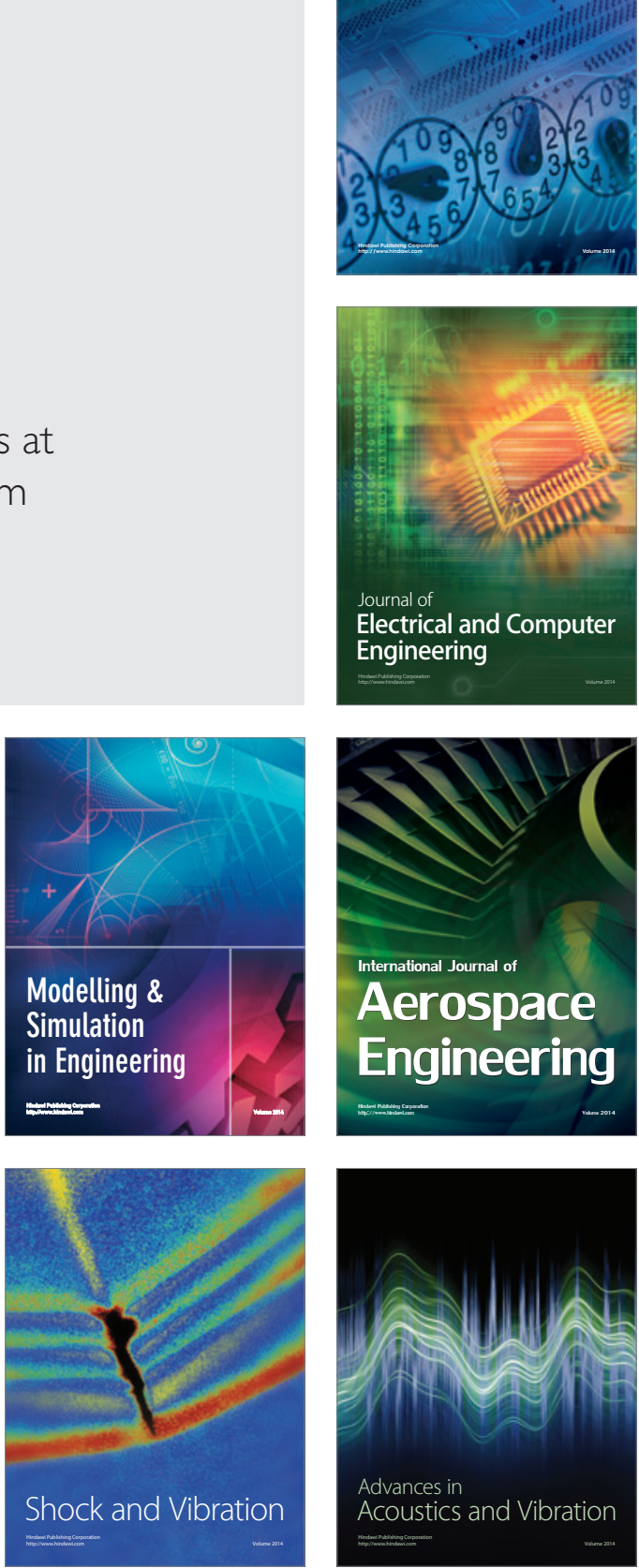